\title{
The Effect of Stem Diameter on the Brassica napus (Type: Canola) (Cultivar: HYHEAR 3) Fiber Quality
}

\author{
Afroza Parvin, Mashiur Rahman, Douglas J. Cattani \\ University of Manitoba, Winnipeg, Canada \\ Email: parvina@myumanitoba.ca,mashiur.rahman@umanitoba.ca,doug.cattani@umanitoba.ca
}

How to cite this paper: Parvin, A., Rahman, M. and Cattani, D.J. (2021) The Effect of Stem Diameter on the Brassica napus (Type: Canola) (Cultivar: HYHEAR 3) Fiber Quality. World Journal of Engineering and Technology, 9, 458-481.

https://doi.org/10.4236/wjet.2021.93031

Received: May 11, 2021

Accepted: July 25, 2021

Published: July 28, 2021

Copyright ( 2021 by author(s) and Scientific Research Publishing Inc. This work is licensed under the Creative Commons Attribution International License (CC BY 4.0).

http://creativecommons.org/licenses/by/4.0/

\begin{abstract}
A matured canola plant has different types of stems based on the diameter, such as narrow (immature), medium (mature), and wide (over mature). Therefore, this study was focused on investigating the properties of the extracted canola (HYREAR 3) fibers from 3 different diameter of stems (narrow, medium and wide). The physical (average length, aspect ratio, contact angle, and moisture regain) and mechanical (load at break, elongation at break, tensile stress, young's modulus, and tenacity) properties of fibers were measured. ANOVA showed that stem diameter had effects on all fiber properties except for average length and elongation at break. Fiber diameter also had significant effects on load at break, elongation at break, aspect ratio, tensile stress, and young's modulus. In corrgram, it was found that tensile stress, young's modulus, and aspect ratio were negatively correlated to fiber diameter whereas load at break and tenacity were positively associated. Mean values showed that stem diameter had effects on all fiber properties except for average length. The mean values of fiber diameter, load at break, elongation at break, tenacity, and contact angle were highest and the lowest mean values were observed for tensile stress, young's modulus and aspect ratio in fibers of $7-10 \mathrm{~mm}$ stems (medium matured), hence found to be less stiff. Moisture regain ability showed that canola fibers isolated from $\geq 8 \mathrm{~mm}$ stem diameter were more hydrophobic whereas contact angle measurement showed relatively more hydrophobic nature of $7-10 \mathrm{~mm}$ stem fibers. Therefore, this study provided an insightful understanding of the quality of the canola fibers of different stems which will ultimately help to choose the best stem to extract different qualities of fibers for commercial uses.
\end{abstract}

\section{Keywords}

Load at Break, Tensile Stress, Young's Modulus, Tenacity, Aspect Ratio, 
Elongation at Break

\section{Introduction}

Natural fibers, that is, plant and animal fibers have different commercial applications. Bast fibers isolated from plant stems, are current research interest due to their high availability [1]. Though at recent times, the use of synthetic fibers is higher [2] [3]. natural fibers gradually replacing the place considering various advantages, such as, better ability to withstand damage, lower cost etc. [1]. In addition, synthetic fiber production process increases the environmental pollution [4] [5]. Therefore, researchers are now focusing on alternative resources to develop fibers that are available, sustainable, and cause minimal environmental damage [1].

Natural fibers have received increasing interest from biocomposite manufacturers for use in various applications due to their wide range of properties [6]. A composite is defined as a physical mixture of two or more materials and exhibits properties that are generally better than those of the individual materials. A suitable combination of materials is required to produce a superior composite, as individual materials alone cannot perform well at an acceptable cost [7]. Current research is focused on developing biocomposites made from flax, hemp, jute, coir, palm, and other natural fibers. Fiber properties can be influenced by a number of factors, including fiber length, maturity, and the processing method used to extract fibers. The internal structure and chemical composition of fiber determine various characteristics such as ultimate tensile strength, Young's modulus, density, and electrical conductivity, among others [8] [9].

Natural fibers can also be used in the textile industries; for example, cotton is the most popular natural textile fiber. Jute is considered the second most important natural bast fiber behind cotton (seed fiber). Jute is primarily used to manufacture cloth, bags and coarse fabrics [10] [11]. Interestingly, not all fibers are suitable for use as textile fibers. A textile fiber must possess certain properties, with given ranges of length, strength, fibrous structure, spinnability, flexibility, cohesiveness, elasticity, fineness, uniformity, luster, color, and the ability to react with acid or alkali [12]. To maintain durability, a fabric knitted by fibers must have a certain level of mechanical strength to tolerate the wear and tear that occurs during regular use [13]. In addition, textile fibers must tolerate spinning stress and tensile force (tenacity) during different stages, such as the winding, warping, sizing, and fabric formation (weaving and knitting) processes applied during manufacturing [14]. Overall, the fabric strength is determined by the fiber strength. The quality of a cellulosic bast fiber may vary due to the intrinsic properties of its natural components, such as the cellulose content, lignin content, fibrous nature, and fiber bundle morphology within plant stems [15] [16]. Among natural fibers, Canadian researchers are currently focusing on canola (Brassica 
napus) fibers, which is a plant bast fiber, for use in industrial applications.

Some recent studies in our lab have investigated the use of this bast fiber for biocomposite production as well as textile applications. These studies include the characterization of canola biomass (fibers) of four cultivars [17], determination of the wicking properties of canola biomass for three growth stages of the canola plants [18], optimization of the retting time and temperature and characterization of canola fibers with alkali, softener, and enzymes for textile applications [19]. The percentages of the important chemicals in Jute and cotton (ideal fiber for textile industries) and also canola fibers are given in Table 1. Considering the types and composition, it is reasonable to find that canola is a lignocellulosic bast fiber [20] because the lignin content (wood fiber content) is much higher and cellulose content is much lower in canola fiber than in cotton and jute fibers, most likely explaining why canola fiber is less flexible than cotton and jute. The maturity of plant stems at different growth stages differs, and hence, the chemical composition (cellulose to lignin ratio) may also differ.

Alcock et al., (2018) have investigated the mechanical properties of flax fibers based on stem maturity [24]. However, there are no corresponding data available for canola plant fibers that are primarily used as waste biomass. If one could distinguish canola fiber qualities based on stem maturity, it would be easier to differentiate the canola stems suitable for further fiber extraction in varying commercial uses. In general, stiffer fibers are primarily used for biocomposite production [25] [26] whereas flexible fibers are mostly used by textile industries [27]. In this study, we focus on the assumption that stiffer fibers are extracted from more mature stems. Therefore, the hypothesis of our study was "narrow diameter stem (immature) of canola plant has less stiff fibers". To test this hypothesis, the current study aimed to investigate the effects of stem diameter on the physical and mechanical properties of canola fibers collected from three groups of stems based on diameter, including narrow (immature), medium (mature), and wide (most mature) stems (Figure 1). This study was focused on a

Table 1. Dominant chemical components of canola and cotton fiber (percentage based on optical density) [21] [22] [23].

\begin{tabular}{cccc}
\hline Component & Canola fiber & Jute fiber & Cotton fiber \\
\hline Cellulose & $44 \%$ & $61 \%-75.5 \%$ & $88 \%-96 \%$ \\
Lignin & $19.21 \%$ & $12 \%-13 \%$ & $0.4 \%-1 \%$ \\
\hline
\end{tabular}

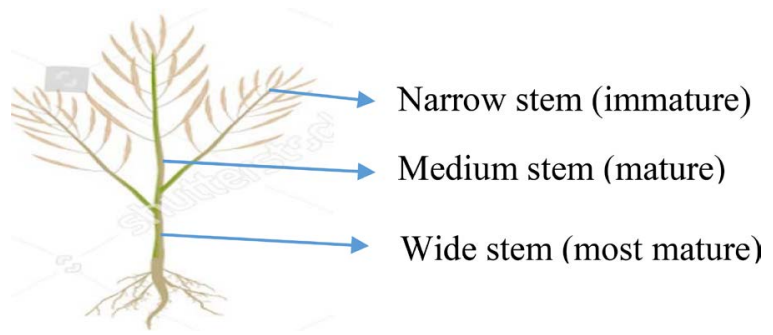

Figure 1. A mature canola plant. 
single type of canola fibers collected from a single cultivar (HYREAR 3), species (Brassica napus), time, and location.

\section{Materials and Methods}

\section{Collection of plant samples}

Brassica napus plants (type: canola) (cultivar: HYREAR 3) were harvested from the field of Carman which was coordinated by the Department of Plant Science, University of Manitoba in the mid of August, 2019. Following harvesting, plant samples were carried out to the textile laboratory located in the Department of Biosystems Engineering at the University of Manitoba were stored at approximately $25^{\circ} \mathrm{C} \pm 2{ }^{\circ} \mathrm{C}$ and $33 \% \pm 2 \%$ relative humidity prior to retting and physical and mechanical characterization.

\section{Retting of plant stems}

In this study, we did total six extractions using same condition for each batch and categorized the stems in three types based on 3 different diameter ranges of stems and each range was separated by at least $0.10 \mathrm{~mm}$. The stem diameter ranges were categorized in 2 groups; in group-1, total 4 extractions were included, such as extraction-1 (E1), extraction-3 (E3), extraction-4 (E4), and extraction-6 (E6) whereas extraction-2 (E2) and extraction-5 (E5) were considered as group-2 (Table 2). Group-1 extractions had nearly similar diameter range and

Table 2. Three different types of stems based on different diameters.

\begin{tabular}{|c|c|c|c|}
\hline Extractions & Stems & Diameter ranges $(\mathrm{mm})$ & Groups \\
\hline \multirow{3}{*}{ E1 } & Narrow & $2.8-4.5$ & \multirow{3}{*}{1} \\
\hline & Medium & $4.8-7.8$ & \\
\hline & Wide & $8.0-10.0$ & \\
\hline \multirow{3}{*}{ E2 } & Narrow & $2.5-6.0$ & \multirow{3}{*}{2} \\
\hline & Medium & $7.0-9.0$ & \\
\hline & Wide & $9.5-12.5$ & \\
\hline \multirow{3}{*}{ E3 } & Narrow & $2.8-4.5$ & \multirow{3}{*}{1} \\
\hline & Medium & $4.8-7.8$ & \\
\hline & Wide & $8.0-10.0$ & \\
\hline \multirow{3}{*}{$\mathrm{E} 4$} & Narrow & $2.8-4.5$ & \multirow{3}{*}{1} \\
\hline & Medium & $4.8-7.8$ & \\
\hline & Wide & $8.0-10.0$ & \\
\hline \multirow{3}{*}{ E5 } & Narrow & $2.5-6.0$ & \multirow{3}{*}{2} \\
\hline & Medium & $7.0-9.0$ & \\
\hline & Wide & $9.5-12.5$ & \\
\hline \multirow{3}{*}{ E6 } & Narrow & $2.8-4.5$ & \multirow{3}{*}{1} \\
\hline & Medium & $4.8-7.8$ & \\
\hline & Wide & $8.0-10.0$ & \\
\hline
\end{tabular}

$\mathrm{NB}: \mathrm{E}=$ Extraction 
so as group-2. Each of the plant stem was cut by around $10 \mathrm{~cm}$ long and the diameters of the stems were measured by a Digital Slide Caliper (Model: MASTERCRAFT, 58-6800-4). All those three categories of stems were then incubated for retting in a water bath (Model: HAAAKE SWB 20, Germany) for $48 \pm 2$ hours at $40^{\circ} \mathrm{C}$.

\section{Estimation of fiber yield (\%)}

The fibers were isolated from the plant stems and then air dried in the lab for approximately 72 hours. The temperature and the relative humidity $(\mathrm{RH})$ of that lab were nearly $25^{\circ} \mathrm{C} \pm 2{ }^{\circ} \mathrm{C}$ and $33 \% \pm 2 \%$, respectively. The weight of the plant stems and the dried fibers was then measured using the following formula for the fiber yield (\%) determination and stored in a small sealed plastic bag in that specific lab for further use.

Fiber yield (\%) of the extracted fibers was calculated using the following formula:

$$
\text { Fiber yield }(\%)=\frac{(\text { Weight of the conditioned fibers after extraction })}{(\text { Weight of conditioned plant stems before retting })} \times 100 \text {. }
$$

\section{Separation of fibers}

The dried fibers were then soaked in distilled water for 10 minutes and individually separated from each other manually using a sharp needle and kept in lab (nearly $25^{\circ} \mathrm{C} \pm 2{ }^{\circ} \mathrm{C}$ temperature and $33 \% \pm 2 \% \mathrm{RH}$ ) for 72 hours. All the extracted and individually separated, dried fibers were packed in a small sealed plastic bag and stored at that specific lab for future use. After separation, 50 individually isolated fibers were prepared for diameter and strength measurement and 30 fibers for contact angle measurement of each stem diameter of a single set. Hence, total 150 fibers from each set were taken for fiber diameter measurement and strength testing and 90 fibers were selected for contact angle measurement (E1, E2, and E4). Another 20 fibers were taken from each set (E3 and E6) to compare and contrast between E1, E3, E4, and E6 and also pooled group$1(\mathrm{E} 1+\mathrm{E} 3+\mathrm{E} 4+\mathrm{E} 6)($ Table 3$)$.

\section{Determination of diameter of fibers}

The diameter of the breaking point of fiber was measured by the Biquant

Table 3. Sample numbers to measure diameter, strength and contact angle.

\begin{tabular}{|c|c|c|c|c|c|c|c|c|c|c|c|c|}
\hline \multirow{3}{*}{ Stems } & \multicolumn{10}{|c|}{ Group-1 } & \multirow{2}{*}{\multicolumn{2}{|c|}{$\begin{array}{c}\text { Group-2 } \\
\text { E2 }\end{array}$}} \\
\hline & \multicolumn{2}{|c|}{ E1 } & \multicolumn{2}{|c|}{ E3 } & \multicolumn{2}{|c|}{ E4 } & \multicolumn{2}{|c|}{ E6 } & \multicolumn{2}{|c|}{$\mathrm{E} 1+\mathrm{E} 3+\mathrm{E} 4+\mathrm{E} 6$} & & \\
\hline & $\mathbf{n}$ & $\mathbf{n}$ & $\mathbf{n}$ & $\mathbf{n}$ & $\mathbf{n}$ & $\mathbf{n}$ & $\mathbf{n}$ & $\mathbf{n}$ & $\mathbf{n}$ & $\mathbf{n}$ & $\mathbf{n}$ & $\mathbf{n}$ \\
\hline Narrow & 50 & 30 & 20 & 20 & 50 & 50 & 20 & 20 & 140 & 100 & 50 & 30 \\
\hline Medium & 50 & 30 & 20 & 20 & 50 & 50 & 20 & 20 & 140 & 100 & 50 & 30 \\
\hline Wide & 50 & 30 & 20 & 20 & 50 & 50 & 20 & 20 & 140 & 100 & 50 & 30 \\
\hline Total & 150 & 90 & 60 & 60 & 150 & 150 & 60 & 60 & 420 & 300 & 150 & 90 \\
\hline
\end{tabular}

N.B: $\mathrm{E}=$ Extraction, $\mathrm{n}=$ number of sample, $\mathrm{D}=$ Diameter, $\mathrm{S}=$ Strength, $\mathrm{CA}=$ Contact Angle. 
Image Analyzer (BIQUANT Image Analysis Corporation, USA). Two (narrowest and widest) readings of the diameter in $\mu \mathrm{m}$ were taken from each fiber. The mean of these two values indicated the final average diameter of the sample. The narrowest diameter was used for strength measurement as it is more likely that the narrowest part of fiber would break mostly and strength of this part was the general case for strength measurement. For contact angle measurement, the average diameter in millimeter $(\mathrm{mm})$ was used.

\section{Determination of strength of fibers}

The fiber breaking load was measured using an Instron Strength Tester (Model: 5965, Massachusetts, USA). The machine was mounted with a 1 Kilo Newton $(\mathrm{KN})$ load cell and fibers were evaluated with an upper crosshead speed of 2 $\mathrm{mm} / \mathrm{min}$ following the principle of constant rate of extension [28]. The sample for measuring the fiber strength was considered as $25.4 \mathrm{~mm}$.

\section{Determination of contact angle (CA) $(\theta)$ of fibers}

The Attention Sigma 700 force Tensiometer (Biolin Scientific, Sweden) determined the dynamic contact angles by dipping (advancing) and withdrawing (receding) a fiber sample in the liquid [29]. In this study, we used average diameter of fibers (taking two diameters from narrowest and widest part of the fibers) and water as liquid to dip the fibers.

\section{Estimation of moisture regain (MR) \% of fibers}

The moisture uptake of the fibers was measured by incubating the extracted fibers in different relative humidity (RH) \% controlled by using desiccators [59]. At first, all the fiber specimens were conditioned in an oven at $(100 \pm 3)^{\circ} \mathrm{C}$ for 4 hours, then weighed and then again conditioned in oven at $(100 \pm 3)^{\circ} \mathrm{C}$ for another 2 hours and measured the weight of the fibers. Similar procedure was repeated for another 1 hour. When the equilibrium weight was found for two consecutive measurement, then the fibers were incubated in desiccator conditioned starting with $11.3 \%$ relative humidity $(\mathrm{RH})$ for 24 hours. Then the specimens were removed from the desiccator, weighed to measure the gained moisture weight, measured the moisture regain (\%) using the following formula and then put back in desiccator for another 24 hours. When the equilibrium weight was found for two consecutive measurements, then the fibers were put in oven again to condition the fibers at $(100 \pm 3)^{\circ} \mathrm{C}$ for 4 hours. The procedure was repeated for another 6 times to measure the moisture regain of fibers for another 6 $\mathrm{RH}(\%)$ conditions counting total $7 \mathrm{RH}$ (\%) conditions. Table 4 presents different parameters used in moisture regain (\%) experiment.

Table 4. Parameter used to estimate moisture regain (MR) \%.

\begin{tabular}{cccccc}
\hline RH (\%) & \multicolumn{2}{c}{$\begin{array}{c}\text { Moisture regain weight } \\
\text { at different } \mathrm{RH}(\%)\end{array}$} & $\begin{array}{c}\text { Oven dry weight at } \\
(100 \pm 3)^{\circ} \mathrm{C}\end{array}$ \\
\cline { 2 - 5 } & 24 hours & 24 hours & $\mathbf{4}$ hours 2 hours 1 hour \\
\hline $11.3 \%, 23.5 \%, 55 \%, 75.5 \%, 84.3 \%, 93.6 \%, 100 \%$ & $\mathrm{~g}$ & $\mathrm{~g}$ & $\mathrm{~g}$ & $\mathrm{~g}$ & $\mathrm{~g}$ \\
\hline
\end{tabular}

N.B: $\%=$ Percentage, $g=$ gram, $\mathrm{RH}=$ Relative Humidity. 
Moisture regain (MR) \% of the extracted fibers were calculated using the following equation:

Moisture regain $(\mathrm{MR}) \%=\frac{(\text { Weight of moisture in the fiber specimen })}{(\text { Weight of oven dried fiber specimen })} \times 100$.

\section{Statistical analysis}

The data were analyzed using the software Microsoft Excel, R 3.5.3, and RStudio for Windows 10 (32/64 bits). One way ANOVA was analyzed using one tail t-test performed by Satterthwaite's method. A probability distribution formed from several independent normal distributions was estimated using this method because the variance estimates were known. Linear mixed model (fiber properties stem diameter) using lmer in RStudio was conducted considering stem diameter as a fixed effect and fiber diameter as a random effect to observe the effect of stem diameter on the fiber properties [30]. The mean and the standard deviations were analyzed and linear model was used to find the differences. On the other hand, to observe the effect of fiber diameter on the fiber properties, the following linear mixed models were used where the random effect was stem diameter and fixed effects were narrowest and average diameter (Table 5). The models were developed using the simple formulas of different parameters. The average length, tenacity, and aspect ratio were analyzed using narrowest diameter and the contact angle was analyzed using average diameter of fibers.

\section{Results and Discussions}

\section{Fiber yield (\%) of the extracted fibers}

The fiber yield (\%) was measured using the total weight of the stems and the retted fibers after extraction and drying. Here, there were six extractions and each extraction contained stems of three separate diameters, and so, there were three different yields (\%) in each extraction. The mean values and the standard deviations were provided in Table 6 for group-1 (E1, E3, E4, and E6) and group-2 (E2 and E5) extractions. Table 7 provided the information of yield (\%) of all individual extractions. The yield (\%) was found between $2.51 \%$ and $4.84 \%$ and it was variable between different stems (narrow, medium and wide) (Table $6 \&$ Table 7). Hence, the stem diameter didn't have any effect on the fiber yield (\%).

Table 5. Models used in this study to test the hypothesis.

\begin{tabular}{cc}
\hline Formulas & Models \\
\hline Tensile stress $=$ Force/Area & avelength/tenacity/aspectratio/contact angle $~$ \\
narrowestdiameter/avediameter \\
Tensile stress $=$ Force/Area & tensilestress $\sim$ loadatbreak $\mathrm{x}$ invarea \\
Young's modulus $=$ Stress $/$ Strain & loadatbreak $\sim$ tensilestress $\mathrm{x}$ invarea \\
Young's modulus $=$ Stress $/$ Strain & youngsmodulus $\sim$ tensilestress $\mathrm{x}$ invtensilestrain \\
\hline
\end{tabular}

N.B: invarea $=$ inverse area, invtensilestrain = inverse tensile strain. 
Table 6. The mean value of fiber yield (\%) of group-1 and group-2 extractions

\begin{tabular}{cccc}
\multicolumn{2}{c}{ Group-1 } & \multicolumn{2}{c}{ Group-2 } \\
E1, E2, E3, and E4 & \multicolumn{2}{c}{ E2 and E5 } \\
\hline Stem diameter & Yield (\%) & Stem diameter & Yield (\%) \\
\hline Narrow & $3.56 \pm 1.16$ & Narrow & $4.07 \pm 0.35$ \\
Medium & $3.41 \pm 0.66$ & Medium & $3.84 \pm 0.68$ \\
Wide & $3.62 \pm 0.74$ & Wide & $3.21 \pm 1.01$ \\
\hline
\end{tabular}

N.B: Mean \pm standard deviation.

Table 7. Fiber yield (\%) of group-1 and group-2 fibers based on different stem diameters.

\begin{tabular}{|c|c|c|c|}
\hline Extractions & Stem diameter & Yield (\%) & Groups \\
\hline & Narrow & 2.51 & \\
\hline \multirow[t]{3}{*}{1} & Medium & 3.17 & 1 \\
\hline & Wide & 2.76 & \\
\hline & Narrow & 3.82 & \\
\hline \multirow[t]{3}{*}{2} & Medium & 3.36 & 2 \\
\hline & Wide & 2.49 & \\
\hline & Narrow & 2.62 & \\
\hline \multirow[t]{3}{*}{3} & Medium & 2.60 & 1 \\
\hline & Wide & 3.23 & \\
\hline & Narrow & 4.28 & \\
\hline \multirow[t]{3}{*}{4} & Medium & 4.07 & 1 \\
\hline & Wide & 4.30 & \\
\hline & Narrow & 4.31 & \\
\hline \multirow[t]{3}{*}{5} & Medium & 4.32 & 2 \\
\hline & Wide & 3.92 & \\
\hline & Narrow & 4.84 & \\
\hline \multirow[t]{2}{*}{6} & Medium & 3.81 & 1 \\
\hline & Wide & 4.17 & \\
\hline
\end{tabular}

Previously in our lab, the fiber yield (\%) of different cultivars of Brassica napus was found between $6.23 \%$ and $13.82 \%$ [29] [31]. In this study, the yield (\%) was found comparatively lower. It might be due to the variations in room humidity condition, water condition, retting time, temperature, and also individual expertise in extraction of fibers. Thinner stems are prone to lodging which enhances the problems of uneven pod maturity and spread of diseases. Photosynthetic capacity of the stems and pods is also significantly decreased by the disease infection, reducing yield (\%) [32]. So, growth condition of plants is also a significant factor to get increased or decreased yield (\%). 
Effects of stem diameter on the physical and mechanical properties of the fibers ( $p$-values)

ANOVA showed that significant $(p<0.05)$ differences were not found between pooled narrow, medium and wide stem fibers taken from E1, E3, E4 and E6 for the properties of average length and elongation at break. Therefore, stem diameter didn't have any effect on average length and elongation at break. However, while other properties such as fiber diameter, load at break, tenacity, tensile stress, young's modulus, aspect ratio, and contact angle were considered, significant differences were observed (Table 8). Therefore, ANOVA showed that stem diameter had effects on fiber properties except fiber diameter, average length, and elongation at break.

Effects of fiber diameter on the physical and mechanical properties of the fibers ( $p$-values)

After ANOVA analysis, insignificant $(p>0.05)$ differences were observed between different fiber diameters for average length in all extractions. Insignificant $(p>0.05)$ differences between different fiber diameters for tenacity in E4 and for contact angle in E2, E3, E4, and E6 were also found. Maximum insignificant ( $p$ > 0.05 ) differences were observed in E3 for elongation at break, load at break, and contact angle including average length. Insignificant $(p>0.05)$ differences were also observed for young's modulus as well as elongation at break in E6. On the other hand, significant $(p<0.05)$ differences for load at break, tenacity, tensile stress, young's modulus, and aspect ratio were observed between different fiber diameters for maximum extractions. This information showed that fiber diameter had strong effects on load at break, tenacity, tensile stress, young's modulus, and aspect ratio. However, elongation at break was moderately and contact angle was poorly influenced by the fiber diameter (Table 9). In this respect, group-1 and group-2 fibers showed almost similar properties.

Table 8. Observation of the effects of stem diameter on the physical and mechanical properties of the fibers ( $p$-values).

\begin{tabular}{cc} 
Properties & $\mathrm{E} 1+\mathrm{E} 3+\mathrm{E} 4+\mathrm{E} 6$ \\
Narrowest diameter $(\mu \mathrm{m})$ & $p$-values \\
Average length $(\mathrm{cm})$ & $7.06 \mathrm{e}^{-07 * * *}$ \\
Elongation at break $(\%)$ & 0.0992 \\
Load at break $(\mathrm{N})$ & 0.259 \\
Tenacity (gf/denier) & $2.08 \mathrm{e}^{-05 * * *}$ \\
Tensile stress $(\mathrm{MPa})$ & $3.66 \mathrm{e}^{-05 * * *}$ \\
Young's modulus $(\mathrm{GPa})$ & $0.000278^{\star * *}$ \\
Aspect ratio $(\mathrm{l} / \mathrm{d})$ & $0.00549^{* *}$ \\
Contact angle $\left({ }^{\circ}\right)$ & $0.000242^{\star * *}$ \\
\hline
\end{tabular}

N.B: $p$-value significance: $0^{\prime * * * 1} 0.001^{\prime * * 1} 0.01^{\prime * 1} 0.05^{\prime}$.' $0.1^{\prime}{ }^{\prime} 1, \mathrm{E}=$ Extraction. 
Relationship between the different variables of group-1 and group-2 fibers using corrgram values

Corrgrams, in their simplest form, are graphical presentations of correlation matrices. The corrgram values of Table 10 showed that the fiber diameter was not related to average length, elongation at break, and contact angle. Load at break and tenacity was positively and moderately correlated to the fiber diameter and tensile stress, young's modulus, and aspect ratio was negatively and moderately correlated to fiber diameter (group-1 and group-2). The results of the corrgram values were nearly consistent with the $p$-values of our current study (Table 8 \& Table 9). Alcock et al., (2018) showed that flax fibers had statistically significant negative correlation with tensile strength differed by stem diameter [24] which is consistent with our current study findings.

Table 9. Observation of the effects of fiber diameter on the physical and mechanical properties of the fibers ( $p$-values).

\begin{tabular}{|c|c|c|c|c|c|}
\hline \multirow{3}{*}{ Properties } & \multicolumn{5}{|c|}{ Fiber diameter } \\
\hline & \multicolumn{4}{|c|}{ Group-1 } & \multirow{2}{*}{$\begin{array}{c}\text { Group-2 } \\
\text { E2 }\end{array}$} \\
\hline & E1 & E3 & E4 & E6 & \\
\hline Average length $(\mathrm{cm})$ & 0.1517 & 0.187 & 0.2751 & 1 & 0.4165 \\
\hline Elongation at break (\%) & $0.000972^{\star * \star}$ & 0.427 & $0.004891^{\star *}$ & 0.350 & $4.24 \mathrm{e}-07^{\star \star *}$ \\
\hline Load at break $(\mathrm{N})$ & $4.407 \mathrm{e}-09^{* * *}$ & 0.307 & $0.005887^{\star *}$ & $0.000976^{\star * *}$ & $0.008426^{* * *}$ \\
\hline Tenacity (gf/Tex) & $0.000457^{\star * *}$ & $0.0297^{\star}$ & 0.5724 & $0.000299^{* * *}$ & $0.01517^{\star}$ \\
\hline Tensile stress $(\mathrm{MPa})$ & $<2 \mathrm{e}-16^{\star * *}$ & $0.0297^{\star}$ & $<2 \mathrm{e}-16^{\star * *}$ & $0.000292^{\star * *}$ & $<2 \mathrm{e}-16^{\star * *}$ \\
\hline Young's modulus (GPa) & $6.825 \mathrm{e}-16^{\star * *}$ & $0.000267^{\star \star \star}$ & $7.262 \mathrm{e}-14^{\star * *}$ & 0.914 & $7.262 \mathrm{e}-14^{* * *}$ \\
\hline Aspect ratio (L/D) & $<2.2 \mathrm{e}-16^{\star * *}$ & $1.28 \mathrm{e}^{-06 * * *}$ & $5.32 \mathrm{e}-11^{\star \star \star}$ & $0.0245^{\star}$ & $<2.2 \mathrm{e}-16^{\star * *}$ \\
\hline Contact angle $\left({ }^{\circ}\right)$ & $0.02345^{*}$ & 0.127 & 0.6861 & 0.358 & 0.6485 \\
\hline
\end{tabular}

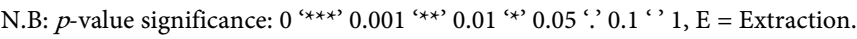

Table 10. Finding the relationship between the variables of group-1 and group-2 fibers.

\begin{tabular}{|c|c|c|c|}
\hline & & Group-1 & Group-2 \\
\hline & Properties & $\begin{array}{c}\mathrm{E} 1+\mathrm{E} 3+\mathrm{E} 4+\mathrm{E} 6 \\
\text { Corrgram values }\end{array}$ & $\begin{array}{c}\text { E2 } \\
\text { Corrgram values }\end{array}$ \\
\hline & Average length $(\mathrm{cm})$ & 0.07 & 0.07 \\
\hline & Elongation at break (\%) & -0.11 & 0.07 \\
\hline \multirow{6}{*}{$\begin{array}{c}\text { Fiber } \\
\text { diameter }\end{array}$} & Contact angle $\left({ }^{\circ}\right)$ & -0.01 & 0.03 \\
\hline & Tensile stress $(\mathrm{MPa})$ & -0.36 & -0.57 \\
\hline & Young's modulus (GPa) & -0.46 & -0.66 \\
\hline & Aspect ratio (L/D) & -0.63 & -0.75 \\
\hline & Load at break $(\mathrm{N})$ & 0.16 & 0.34 \\
\hline & Tenacity (gf/Tex) & 0.16 & 0.22 \\
\hline
\end{tabular}

N.B: $\mathrm{E}=$ Extraction. 


\section{The relationship between fiber properties and stem diameter using mean values}

In this study, a difference in physical and mechanical performance was found between narrow, medium and wide stem fibers that were separated by at least $0.10 \mathrm{~mm}$ range (Table 2 ). These large variations in stem diameters might cause large standard deviations during fiber tensile properties [24] [31]. To reduce the large standard deviations, data were transformed to square root and squared again to get the relative value.

\section{Effects of stem diameter on canola fiber diameter}

Table 11 is showing the physical and the mechanical properties of cotton and jute fibers and Table $12 \&$ Table 13 is showing the mean values of narrowest and average diameter of the fibers isolated from narrow, medium and wide stems of group-1 and group-2 (E2) fibers. The mean values for narrowest diameter ranged from $(44.19$ - 59.91) $\mu \mathrm{m}$ and the mean values for average diameter

Table 11. Physical and mechanical properties of cotton Cotton: [33] [34] [35] [36] and Jute: [10] [33] [37] [38] [39] [40] [41]

\begin{tabular}{lcccccccccc}
\hline Fibers & $\begin{array}{c}\text { Diameter } \\
(\mu \mathrm{m})\end{array}$ & $\begin{array}{c}\text { Length } \\
(\mathrm{cm})\end{array}$ & $\begin{array}{c}\text { Moiture } \\
\text { Regain } \\
(\%)\end{array}$ & $\begin{array}{c}\text { Contact angle } \\
\left({ }^{\circ}\right)\end{array}$ & $\begin{array}{c}\text { Elongation } \\
\text { at break } \\
(\%)\end{array}$ & $\begin{array}{c}\text { Load at } \\
\text { break } \\
(\mathrm{N})\end{array}$ & $\begin{array}{c}\text { Tenacity } \\
(\mathrm{gf} / \mathrm{tex})\end{array}$ & $\begin{array}{c}\text { Tensile } \\
\text { stress } \\
(\mathrm{MPa})\end{array}$ & $\begin{array}{c}\text { Young's } \\
\text { modulus } \\
(\mathrm{GPa})\end{array}$ & $\begin{array}{c}\text { Aspect } \\
\text { ratio } \\
(\mathrm{L} / \mathrm{D})\end{array}$ \\
\hline Cotton & $14-21$ & $1.5-5.6$ & 8.5 & $\begin{array}{c}\sim 0(\text { control) } \\
156.3 \text { (treated) }\end{array}$ & $3-12$ & $1.63-1.97$ & $1.7-6.3$ & $287-597$ & 4.8 & 1400 \\
Jute & $12-18$ & $100-400$ & $10-12$ & $36-42$ & $1.69-1.83$ & 31.63 & $26.5-51.2$ & $300-700$ & $20-50$ & 150 \\
\hline
\end{tabular}

Table 12. The mean values of narrowest diameters of group-1 and group-2 fibers used in this study.

\begin{tabular}{ccc}
\hline & \multicolumn{2}{c}{$\begin{array}{c}\text { Narrowest diameter }(\mu \mathrm{m}) \\
\text { (used for tensile strength measurement) }\end{array}$} \\
\cline { 2 - 3 } Stems & $\begin{array}{c}\text { Group-1 } \\
\text { E1 }+ \text { E3 }+ \text { E4 + E6 }\end{array}$ & Group-2 \\
E2
\end{tabular}

N.B: Mean \pm standard deviation, $\mathrm{E}=$ Extraction, $\mu \mathrm{m}=$ Micrometer.

Table 13. The mean values of average diameters of group-1 and group-2 fibers used in this study.

\begin{tabular}{ccc}
\hline & \multicolumn{2}{c}{$\begin{array}{c}\text { Average diameter }(\mu \mathrm{m}) \\
\text { (used for contact angle measurement) }\end{array}$} \\
\cline { 2 - 3 } Stems & $\begin{array}{c}\text { Group-1 } \\
\text { E1 }+\mathrm{E} 3+\mathrm{E} 4+\mathrm{E} 6\end{array}$ & $\begin{array}{c}\text { Group-2 } \\
\text { E2 }\end{array}$ \\
Narrow & $0.09 \pm 0.02$ & $0.09 \pm 0.03$ \\
Medium & $0.08 \pm 0.03$ & $0.10 \pm 0.03$ \\
Wide & $0.09 \pm 0.02$ & $0.08 \pm 0.02$ \\
\hline
\end{tabular}

N.B: Mean \pm standard deviation, $\mathrm{E}=$ Extraction, $\mathrm{mm}=$ Milimeter. 
ranged from $(0.08-0.10) \mathrm{mm}$. The highest mean value of narrowest and average diameter of wide stem fibers of cumulative extractions of group-1 and medium stem fibers of group-2 (E2) was found. The diameter for cotton fibers is $14-21$ $\mu \mathrm{m}$ and jute is $12-18 \mu \mathrm{m}$ which are significantly lower than the canola fibers (Table 12 \& Table 13). Therefore, canola fiber diameter might affect its application as textile fibers.

\section{Effects of stem diameter on canola fiber length}

The canola fiber average length mean values ranged from $4.78-5.85 \mathrm{~cm}$ which was near to cotton fiber length $(1.5-5.6 \mathrm{~cm})$ and much lower than the jute fiber length $(100-400 \mathrm{~cm})$ (Table $11 \&$ Table 14). There was no correlation was observed between narrow, medium, and wide stem fiber length of group-1 and group-2 (E2) fibers and the mean values were found highly variable. Therefore, stem diameter didn't have any effect on average length of fibers. Fiber length is one of the most important characteristics in productivity of textile manufacturing, such as, most of the shorter fibers (e.g. $<4-5 \mathrm{~mm}$ ) usually waste in the manufacturing process. Fibers with $5-15 \mathrm{~mm}$ in length give the fullness of the yarn rather than its strength, whereas fibers above $12-15 \mathrm{~mm}$ long contribute to yarn strength and survive carding without significant shortening [42]. Therefore, $4.78-5.85 \mathrm{~cm}$ canola fiber length might be able to show those properties while using for textile applications.

\section{Effects of stem diameter on canola fiber elongation at break}

In this study, the elongation at break for canola was found $1.56 \%-1.83 \%$ which was relatively lower than the cotton elongation at break $(3 \%-12 \%)$ and nearly similar to jute elongation at break $(1.69 \%-1.83 \%)$. Bast and leaf fibers have lower elongation at break (\%) than seed, stalk, or industrially man-made fibers [43]. In this study, elongation at break (\%) for wide stem fibers of cumulative extractions of group-1 and group-2 (E2) was found highest (Table 15) making the fibers relatively less stiff. Because fibers with high elongation at break show lower strength and Young's modulus. Higher elongation at break (\%) means lower ability to resist changes, thus, enhancing relative flexibility [43]. Elasticity is a significant character in textile fibers, because textile products must have the ability to stretch and reform after deformation, for example, in the elbow of a garment. Therefore, the fiber elongation at break (\%) should be at least 1\% $2 \%$ which was consistent with our present study. With much higher elongation

Table 14. Observation of the effects of stem diameter on average length.

\begin{tabular}{ccc}
\hline & \multicolumn{2}{c}{ Average length $(\mathrm{cm})$} \\
\cline { 2 - 3 } Stems & Group-1 & Group-2 \\
& E1 + E3 + E4 + E6 & E2 \\
\hline Narrow & $5.85 \pm 1.54$ & $5.08 \pm 0.96$ \\
Medium & $5.77 \pm 1.58$ & $5.02 \pm 1.17$ \\
Wide & $5.46 \pm 1.72$ & $4.78 \pm 1.12$ \\
\hline
\end{tabular}

N.B: Mean \pm standard deviation, $\mathrm{E}=$ Extraction. 
Table 15. Observation of the effects of stem diameter on elongation at break.

\begin{tabular}{ccc}
\hline & \multicolumn{2}{c}{ Elongation at break (\%) } \\
\cline { 2 - 3 } Stems & Group-1 & Group-2 \\
& E1 + E3 + E4 + E6 & $1.56 \pm 0.12$ \\
Narrow & $1.67 \pm 0.09$ & $1.80 \pm 0.11$ \\
Medium & $1.71 \pm 0.09$ & $1.64 \pm 0.10$ \\
Wide & $1.83 \pm 0.07$ & \\
\hline
\end{tabular}

N.B: Mean \pm standard deviation, $\mathrm{E}=$ Extraction.

values $(15 \%-30 \%)$ in synthetic fibers often have spinning and drafting difficulties [42]. Elongation at break showed that wide stem fibers of group-1 and medium stem fibers of group-2 (E2) canola fibers might be useful for textile applications.

\section{Effects of stem diameter on canola fiber load at break and tenacity}

The load at break and tenacity were found in canola fibers $0.38-0.76$ and 0.40 - $0.77 \mathrm{gf} / \mathrm{tex}$, respectively. In cotton fibers, the load at break and tenacity were found $1.63-1.97 \mathrm{~N}$ and $1.7-6.3 \mathrm{gf} / \mathrm{tex}$, respectively which was higher than canola fibers. On the contrary, in jute fibers, the load at break and tenacity were found $31.63 \mathrm{~N}$ and $26.5-51.2 \mathrm{gf} / \mathrm{tex}$, respectively which was much higher than canola fibers (Table 11, Table 16, \& Table 17). In a fabric, as the tearing force/breaking load increases, the specific tightness of the yarns decreases and flexibility of yarn increases [44]. In the manufacturing of industrial fabrics, the high tenacity yarn is very useful, especially airbag fabrics [45] [46]. Therefore, high load at break and tenacity of fiber are important characteristics for the flexibility or elasticity of fibers to make yarn. Generally, stiffer fibers are used for composite productions [47] and flexible fibers are useful for textile applications [48]. In this study, load at break, and tenacity for wide stem fibers of cumulative extractions of group-1 and medium stem fibers of group-2 (E2) was found highest (Table 16 and Table 17) making the fibers relatively more flexible and less stiff and useful for textile applications.

Effects of stem diameter on canola fiber tensile stress and young's modulus

The average tensile stress for cotton is $287-597 \mathrm{MPa}$ and jute is $300-700$ $\mathrm{MPa}$ and for canola fiber, it was found 192 - $358 \mathrm{MPa}$ which was overlapping to cotton and jute but shifted lower for canola. The average young's modulus for cotton is $4.8 \mathrm{GPa}$ and jute is $20-50 \mathrm{GPa}$ and for canola fiber, it was observed 20 - $37 \mathrm{GPa}$ which was predominantly higher than cotton and overlapping to jute (Table 18 \& Table 19). Prasad and Sain (2016) studied on hemp fibers as a raw material of composite productions and observed that the mechanical properties (tensile stress and young's modulus) of natural lignocellulosic hemp fibers were found to be dependent on the fiber diameter reducing with gradual increase in fiber diameter [48]. This is also consistent with the general observation found in synthetic fibers, where the fiber diameter decreases and the amount of internal 
Table 16. Observation of the effects of stem diameter on load at break (mean-values).

\begin{tabular}{ccc}
\hline & \multicolumn{2}{c}{ Load at break (N) } \\
\cline { 2 - 3 } Stems & $\begin{array}{c}\text { Group-1 } \\
\text { E1 + E3 + E4 + E6 }\end{array}$ & Group-2 \\
Narrow & $0.45 \pm 0.05$ & $0.38 \pm 0.02$ \\
Medium & $0.55 \pm 0.06$ & $0.49 \pm 0.05$ \\
Wide & $0.76 \pm 0.27$ & $0.40 \pm 0.04$ \\
\hline
\end{tabular}

N.B: Mean \pm standard deviation, $\mathrm{E}=$ Extraction.

Table 17. Observation of the effects of stem diameter on tenacity (mean-values).

\begin{tabular}{ccc}
\hline & \multicolumn{2}{c}{ Tenacity (gf/tex) } \\
\cline { 2 - 3 } Stems & Group-1 & Group-2 \\
& E1 + E3 + E4 + E6 & E2 \\
\hline Narrow & $0.46 \pm 0.05$ & $0.40 \pm 0.02$ \\
Medium & $0.56 \pm 0.08$ & $0.50 \pm 0.06$ \\
Wide & $0.77 \pm 0.08$ & $0.44 \pm 0.04$ \\
\hline
\end{tabular}

N.B: Mean \pm standard deviation, $E=$ Extraction.

Table 18. Observation of the effects of stem diameter on tensile stress (mean-values).

\begin{tabular}{ccc}
\hline & \multicolumn{2}{c}{ Tensile stress (MPa) } \\
\cline { 2 - 3 } Stems & $\begin{array}{c}\text { Group-1 } \\
\text { E1 }+ \text { E3 + E4 + E6 }\end{array}$ & Group-2 \\
Narrow & $313.92 \pm 49.9$ & $228.31 \pm 28.41$ \\
Medium & $358.74 \pm 48.96$ & $192.38 \pm 22.28$ \\
Wide & $238.35 \pm 40.11$ & $196 \pm 30.47$ \\
\hline
\end{tabular}

N.B: Mean \pm standard deviation, $\mathrm{E}=$ Extraction

Table 19. Observation of the effects of stem diameter on young's modulus (mean-values).

\begin{tabular}{ccc}
\hline & \multicolumn{2}{c}{ Young's modulus (GPa) } \\
\cline { 2 - 3 } Stems & Group-1 & Group-2 \\
& E1 + E3 + E4 + E6 & E2 \\
\hline Narrow & $33.47 \pm 4.15$ & $26.73 \pm 2.40$ \\
Medium & $37.51 \pm 4.55$ & $20.25 \pm 3.13$ \\
Wide & $30.17 \pm 3.15$ & $22.56 \pm 2.76$
\end{tabular}

N.B: Mean \pm standard deviation, $E=$ Extraction.

flaws in the fibers also decreases, thus increasing the tensile stress and young's modulus of fibers. For example, the mean tensile strength and young's modulus of fibers were $4200 \mathrm{MPa}$ and $180 \mathrm{GPa}$, respectively for hemp fibers with $4 \mu \mathrm{m}$ diameter. For fibers with $66 \mu \mathrm{m}$ diameter, these values reduced to $250 \mathrm{MPa}$ and $11 \mathrm{GPa}$, respectively. For $800 \mu \mathrm{m}$ diameter fibers, the values decreased to $10 \mathrm{MPa}$ for tensile strength and $2 \mathrm{GPa}$ for tensile modulus. Shahzad (2013) observed that 
hemp fibers with diameter of $67 \mu \mathrm{m}$ had $277 \mathrm{MPa}$ tensile stress and 9.5 GPa young's modulus to find their compatibility to be used as reinforcement in composite materials [49].

Our results were consistent with these findings for wide stem fibers of cumulative extractions of group-1 and medium stem fibers of group-2 (E2). Because the wide stem fibers of group-1 and medium stem fibers of group-2 (E2) had highest fiber diameter, but the tensile stress and young's modulus were found lowest (Table 11, Table 18 \& Table 19). Therefore, those fibers had lowest twisting moment force (tensile strength) and lowest ability to withstand changes, hence, the amount of internal flaws were also lowest for those fibers. Moreover, a flexible material has a low Young's modulus and changes its shape considerably (e.g. rubbers) [50] [51]. This quality indicated that wide stem fibers of group-1 and medium stem fibers of group-2 were less stiff making relatively suitable for textile applications than the narrow and medium stem fibers of group-1 and narrow and wide stem fibers of group-2. Interestingly, the observations were found by Prasad and Sain in 2003 and Shahzad in 2013 were not consistent with our findings for the fibers of narrow and medium stem fibers of group-1 and wide stem fibers of group-2, where with the reducing fiber diameter, the tensile stress and young's modulus fluctuated [48] [49].

\section{Effects of stem diameter on canola fiber aspect ratio}

In short-fiber reinforced rubber, when the fiber aspect ratio (300) is higher, the tensile stress and young's modulus in rubber is also higher on a specific length. Therefore, fiber with high aspect ratio is good for strengthening the fiber reinforced rubber. However, if the fiber aspect ratio exceeds 400, the tensile stress and young's modulus decreases due to uneven dispersion of fibers in rubber on a specific length [52]. In this study, the aspect ratio for canola fibers found to be significantly higher (8606-13413) (Table 20), because the fiber length of this study was found higher. Cotton fibers also have relatively higher aspect ratio (1400), however, the aspect ratio for jute (150) is much lower which seems to be good for textile applications (Table 11). In general, the aspect ratio for natural fibers seems to be higher and the threshold level of aspect ratio for canola fibers for different applications would be different. In this study, the aspect ratio for wide stem fibers of cumulative extractions of group- 1 and medium stem fibers of group-2 (E2) was found lowest (Table 20) than the other stem

Table 20. Observation of the effects of stem diameter on aspect ratio (mean-values).

\begin{tabular}{ccc}
\hline & \multicolumn{2}{c}{ Aspect ratio (L/D) } \\
\cline { 2 - 3 } Stems & Group-1 & Group-2 \\
& E1 + E3 + E4 + E6 & E2 \\
\hline Narrow & $13,413.33 \pm 454.56$ & $10,840.97 \pm 412.09$ \\
Medium & $12,821.44 \pm 450.13$ & $8606.27 \pm 256.32$ \\
Wide & $10,462.2 \pm 482.65$ & $9289.10 \pm 382.59$ \\
\hline
\end{tabular}

N.B: Mean \pm standard deviation, $\mathrm{E}=$ Extraction. 
fibers making the fibers relatively less likely to produce composites and more likely to be used in textile applications. It is also important to note that aspect ratio can be controlled by controlling the length of bast fibers, composites, and apparels.

\section{Effects of stem diameter on canola fiber contact angle}

Untreated cotton fabric contact angle is near to zero and its super hydrophilic in normal condition, however, by grafting graphene oxide on cotton fabric, the hydrophilic functional groups removed from its surface area, as result the fabric wettability and absorbency reduced considerably [53] and so, its contact angle turned higher (super hydrophobic, contact angle $>150^{\circ}$ ) and the contact angle for jute fiber is $36^{\circ}-42^{\circ}$ which is super hydrophilic (Table 11). Therefore, treated cotton fiber relative moisture gain reduced retaining its original quality for long at different atmospheric conditions [29] [53]. In our study, contact angle found for control canola fiber was found $112^{\circ}-127^{\circ}$ which was far higher than control cotton and jute and the highest contact angle was found in the wide stem fibers of cumulative extractions of group-1 and medium stem fibers of group-2 (E2) (Table 21) making them more hydrophobic like treated cotton and ability to retain its original quality for long. Therefore, contact angle revealed that wide stem fibers of cumulative extractions of group- 1 and medium stem fibers of group-2 (E2) were relatively more hydrophobic in nature retaining its original quality for long.

In summary, mean values showed that stem diameter had effects on fiber properties (except average length) including fiber diameter. The mean values of elongation at break (Table 15), load at break (Table 16), tenacity (Table 17), and contact angle (Table 21) were highest for wide stem fibers of cumulative extractions of group-1 and medium stem fibers of group-2 (E2). On the contrary, the mean values of tensile stress (Table 18), young's modulus (Table 19), and aspect ratio (Table 20) were found to be lowest for wide stem fibers of cumulative extractions of group-1 and medium stem fibers of group-2 (E2). For average length, no correlation was observed of canola fiber mean values with stem diameter (Table 14). It is interesting to note that though stem diameter had neutral effect on average length of fibers, however, some effect was found in aspect ratio (Table 20). Significant $(p<0.05)$ differences were found between properties of group-1 and group-2 fibers when a linear model was used.

Table 21. Observation of the effects of stem diameter on contact angle (mean-values).

\begin{tabular}{ccc}
\hline & \multicolumn{2}{c}{${\text { Contact angle }\left(^{\circ}\right)}^{2}$} \\
\cline { 2 - 3 } Stems & Group-1 & Group-2 \\
& E1 + E3 + E4 + E6 & E2 \\
\hline Narrow & $112.16 \pm 10.80$ & $113.28 \pm 7.91$ \\
Medium & $117.8 \pm 16.03$ & $127.78 \pm 14.33$ \\
Wide & $126.11 \pm 20.8$ & $118.35 \pm 12.85$ \\
\hline
\end{tabular}

N.B: Mean \pm standard deviation, $\mathrm{E}=$ Extraction. 
All those properties of canola fibers comparing with the values of cotton and jute showed that the mean values of wide stem fibers of cumulative extractions of group-1 and medium stem fibers of group-2 (E2) were close to cotton and jute (Table 11) and hence, making the physical and mechanical properties relatively close to cotton and jute than the narrow and medium stem fibers of group- 1 and narrow and wide stem fibers of group-2. Here, it is important to note that the diameter range of wide stem $(8-10 \mathrm{~mm})$ fibers of group- 1 and the medium stem $(7-9 \mathrm{~mm})$ fibers of group-2 was almost similar and fell between $7 \mathrm{~mm}$ to $10 \mathrm{~mm}$ (Table 2).

\section{Quality of middle portion stem fibers}

The flax fiber tensile properties varies with the stem diameter of flax plants and the fibers with best tensile performance occurs in the middle portion of the stem [54] which is consistent with our present study findings (7 - $10 \mathrm{~mm}$ diameter stem) (Table 2 \& Tables 11-21). Bourmaud et al., (2016) found that the fiber diameter decreases from the bottom to the top of the stem which doesn't go with our present study findings, it might be due to the variation in the chemical composition of canola and flax fibers [55].

Charlet et al. in 2007 and in 2009 explained that the middle stem fiber cell walls contain the highest contents of both cellulose and non-cellulosic polymers which helps the load transfer from one microfibril to another. When fibers isolated from similar diameter stems from different portions of the stem were compared, the mechanical differences were still found. The differences might be due to the differences in growing conditions where the bottom and top fibers are usually developed in a less desirable or interrupted growing conditions [54] [56]. Moreover, thinner (topper) stems are prone to lodging which enhances the problems of uneven stem and pod maturity and spread of diseases [32]. Interestingly, in our present study, we also found the differences in mechanical properties of fibers taken from similar diameter stems from different sections except the 7 - 10 mm diameter stems (Table $2 \&$ Tables 11-21). Because the chemical composition within $7-10 \mathrm{~mm}$ stem fibers might be similar. Alcock et al., (2018) also found that samples with the same stem diameter range had no correlations for tensile strength, young's modulus or fiber diameter that were grown in different locations or were of different varieties, but had correlation grown within same location and same variety [24] which is also consistent with our current findings as well. Because the stems of the present study were collected from same canola field and same variety (HYREAR 3).

A natural fiber (e.g. cotton) consists of a cell wall and lumen and the fiber turns to more mature as the cell wall thickens. A moisture-swollen mature cotton fiber cell wall comprises $50 \%-80 \%$ of the fiber cross-section whereas immature cotton fiber comprises $30 \%-45 \%$ and dead cotton fiber has less than $25 \%$. Industrial cotton stock does not include too many immature or dead fibers due to lack of adequate strength which can lead to problems such as loss of yarn strength, variable dye uptake and processing difficulties [42]. In our study, 7 - 10 
$\mathrm{mm}$ canola stem fibers were found to be relatively more useful for textile applications rather than other types of stem fibers.

\section{Effect of stem diameter on fiber moisture regain (MR) \%}

The increasing trend of MR (\%) was observed for $11.3 \%, 23.5 \%, 55 \%, 75.5 \%$, $84.3 \%, 93.6 \%$ RH. On the other hand, a decreased trend in MR (\%) was found at $100 \% \mathrm{RH}$ (Figure 2 and Figure 3). At saturated condition, fiber moisture regain capacity might be decreased. So, the MR (\%) of canola fibers changed with the change in RH (\%) which is also true for other natural fibers [57] [58]. The pattern is similar for all wide, medium, and narrow stem fibers of E1, E4, E2, and

E1

Fibers of wide, medium \& narrow stems

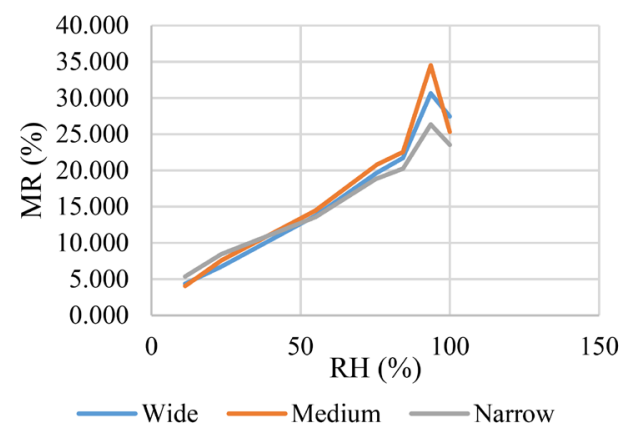

(a)
E4

Fibers of wide, medium \& narrow stems

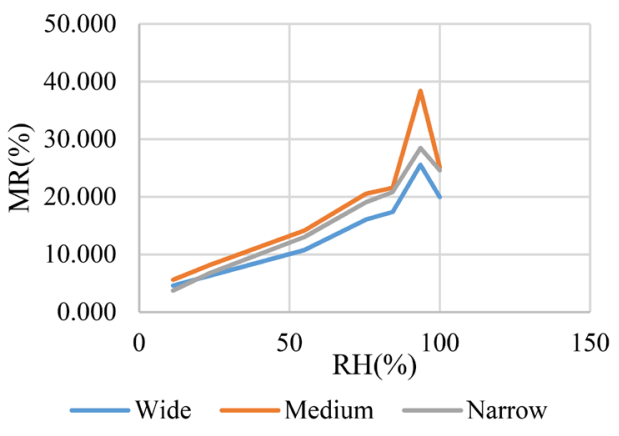

(b)

Figure 2. Effect of fiber moisture regain (MR) \% on stem diameter of group-1 fibers. (a) Wide, medium, and narrow stem fibers of E1, (b) Wide, medium, and narrow stem fibers of E4. The MR (\%) increased with the increasing RH (\%) except for 100\% RH condition. The MR (\%) was found to be lowest for wide stem fibers of E1 and E4 in most of the cases.

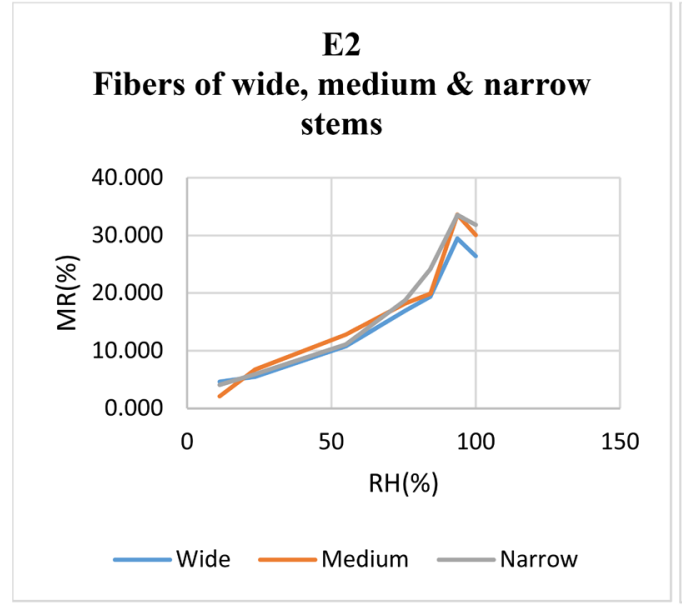

(a)

\section{E5}

Fibers of wide, medium \& narrow stems

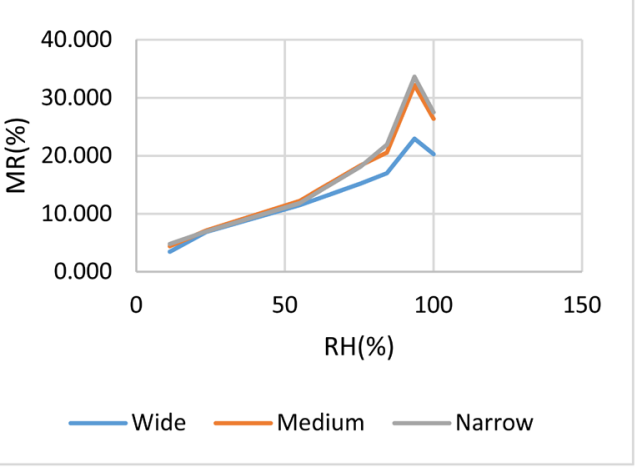

(b)

Figure 3. Effect of fiber moisture regain (MR) \% on stem diameter of group-2 fibers. (a) Wide, medium, and narrow stem fibers of E2, (b) Wide, medium, and narrow stem fibers of E5 The MR (\%) increased with the increasing RH (\%) except for 100\% RH condition. The MR (\%) was found to be lowest for wide stem fibers of E2 and E5 in most of the cases. 
E5. It is important to note that the stem diameter range was similar between E1 and E4 and between E2 and E5 (Table 2). Therefore, the mean value for each type of stem fibers was calculated taking the values from E1 and E4 and from E2 and E5. Lowest mean value of MR (\%) was observed for wide stem fibers of E1, E4, E2, and E5 which showed that fibers taken from $\geq 8 \mathrm{~mm}$ stem diameter were relatively more hydrophobic in nature than the fibers isolated from $<8 \mathrm{~mm}$ stem diameter. The differences between mean values of E1, E4 and E2, E5 fibers were found statistically significant $(p<0.05)$ when a linear model was used.

Contact angle showed that $8-10 \mathrm{~mm}$ stem fibers were relatively more hydrophobic which was somewhat consistent with the moisture regain ability found in this study. The MR (\%) experiment showed less hydrophobicity in the control canola fibers than the relative hydrophobicity found in control fibers by contact angle measurement. Control cotton fibers are hydrophilic whereas treated fibers are hydrophobic (Table 11). Therefore, this study revealed that moisture regain experiment is better than contact angle experiment for canola fiber relative hydrophilicity measurement.

\section{Conclusion}

The stem diameter did not have any effect on the fiber yield (\%). However, ANOVA showed that stem diameter had effects on all fiber properties except for average length and elongation at break. ANOVA also showed that fiber diameter had strong effects on elongation at break, load at break, tensile stress, young's modulus, and aspect ratio. However, tenacity was moderately and contact angle was poorly and average length was not influenced by the fiber diameter. Fiber diameter was moderately and positively correlated to tenacity and load at break whereas fiber diameter was moderately and negatively correlated to tensile stress, young's modulus and aspect ratio observed by corrgram. Mean values showed that stem diameter had effects on fiber properties except average length. The mean values of elongation at break (\%), load at break, tenacity, and contact angle (hydrophobicity) were found to be highest and the mean values of tensile stress, young's modulus, and aspect ratio were found to be lowest for 7 - $10 \mathrm{~mm}$ stem fibers of canola plant. Interestingly, those properties were relatively closed to the properties of cotton and jute fibers as well. In most cases, lowest MR (\%) was found for wide stem fibers of all extractions which showed that fibers collected from $\geq 8 \mathrm{~mm}$ stems were relatively more hydrophobic. Contact angle showed that 7 - $10 \mathrm{~mm}$ stem fibers were relatively more hydrophobic which was somewhat consistent with the moisture regain ability. Considering all those facts, it was observed that $7-10 \mathrm{~mm}$ stem fibers of canola plant were relatively less stiff and were able to retain its quality for long time. Overall, this study suggested to sort out different qualities of canola fibers of different stem diameters for different commercial applications. In future, it would be interesting to observe the cellulose and lignin content ratio of canola fibers based on different stems to find out the exact reason of the fiber flexibility of $7-10 \mathrm{~mm}$ stems. 


\section{Acknowledgements}

We are thankful to the personnel of the Textile Laboratory of the Department of Biosystems Engineering, University of Manitoba for providing the necessary logistic support and training.

\section{Conflicts of Interest}

The authors declare no conflicts of interest regarding the publication of this paper.

\section{References}

[1] Thomas, S., Paul, S.A., Pothan, L.A. and Deepa, B. (2011) Natural Fibres: Structure, Properties and Applications. In: Kalia, S., Kaith, B.S. and Kaur, I., Eds., Cellulose Fibers. Bio- and Nano-Polymer Composites. Green Chemistry and Technology, Springer, Berlin, 3-42. https://doi.org/10.1007/978-3-642-17370-7_1

[2] Carmichael, A. (2015) Man-Made Fibers Continue to Grow. Textile World, 165, 20.

[3] Tortora, P.G. (1997) Understanding Textiles. 5th Edition, Merrill, Upper Saddle River.

[4] Rana, S., Pichandi, S., Parveen, S. and Fangueiro, R. (2014) Natural Plant Fibers: Production, Processing, Properties and Their Sustainability Parameters. In: Muthu, S.S., Ed., Roadmap to Sustainable Textiles and Clothing. Eco-Friendly Raw Materials, Technologies, and Processing Methods, Springer, Singapore, 1-35. https://doi.org/10.1007/978-981-287-065-0 1

[5] Shen, L., Worrell, E. and Patel, M. (2010) Environmental Impact Assessment of ManMade Cellulose Fibres. Resources, Conservation and Recycling, 55, 260-274. https://doi.org/10.1016/j.resconrec.2010.10.001

[6] Bledzki, A.K. and Gassan, J. (1999) Composites Reinforced with Cellulose Based Fibres. Progress in Polymer Science, 24, 221-274. https://doi.org/10.1016/S0079-6700(98)00018-5

[7] Hautala, M., Pasila, A. and Pirilä, J. (2004) Use of Hemp and Flax in Composite Manufacture: A Search for New Production Methods. Composites Part A: Applied Science and Manufacturing, 35, 11-16. https://doi.org/10.1016/j.compositesa.2003.09.023

[8] Mohanty, A.K., Misra, M. and Drzal, L.T. (2001) Surface Modifications of Natural Fibers and Performance of the Resulting Biocomposites: An Overview. Composite Interfaces, 8, 313-343. https://doi.org/10.1163/156855401753255422

[9] Reddy, N. and Yang, Y. (2005) Biofibers from Agricultural Byproducts for Industrial Applications. Trends in Biotechnology, 23, 22-27. https://doi.org/10.1016/j.tibtech.2004.11.002

[10] Mia, R., Islam, M.A., Ahmed, B. and Mojumdar, J.I.A. (2017) Woolenization of Jute Fibre. European Scientific Journal, 13, 314-326. https://doi.org/10.19044/esj.2017.v13n30p314

[11] Anwar, A. (2007) Information on Jute, Kenaf, Roselle Hemp and Natural/Bast Fiber Textile Products-by GFTCL. http://exporter-of-jute-products.blogspot.com

[12] Sayed Bin, Z., Islam, T., Chawdhury, N.H. and Ahmed, M. (2018) Effect of Knitted Structures and Yarn Count on the Properties of Weft Knitted Fabrics. Journal of Textile Science and Technology, 4, 67-77. https://doi.org/10.4236/jtst.2018.42004

[13] Hatch, K.L. (1993) Fiber Properties and Identification. In: Textile Science, West Publishing, Saint Paul, 108-127. 
[14] Booth, J.E. (1968) Principles of Textile Testing: An Introduction to Physical Methods of Testing Textile Fibres, Yarns and Fabrics. Heywood Books, London, 570.

[15] Bonatti-Chaves, M., Karnopp, P., Soares, H. and Furlan, S. (2004) Evaluation of Pleurotus ostreatus and Pleurotus sajor-caju Nutritional Characteristics When Cultivated in Different Lignocellulosic Wastes. Food Chemistry, 88, 425-428. https://doi.org/10.1016/j.foodchem.2004.01.050

[16] Rowell, R.M., Han, J.S. and Rowell, J.S. (2000) Characterization and Factors Effecting Fiber Properties. In: Natural Polymers an Agrofibers Composites, Embrapa Instrumentação Agropecurária, São Carlos, 115-134.

[17] Shuvo, I.I., Rahman, M., Vahora, T., Morrison, J., DuCharme, S. and Choo-Smith, L.-P. (2019) Producing Light-Weight Bast Fibers from Canola Biomass for Technical Textiles. Textile Research Journal, 90, 11-12. https://doi.org/10.1177/0040517519886636

[18] Soriano, L. and Rahman, M. (2017) Wicking Properties of Brassica Fiber in Three Different Growth Stages Wicking Properties of Brassica Fiber in Three Different Growth. Proceedings on Canadian Society for Bioengineering Annual General Meeting and Conference 2017, Winnipeg, Manitoba, 6-10 August 2017.

[19] Khan, M.R.I. (2016) Evaluation of Brassica Fibre for Textile and Spinning Properties. Master's Thesis, Department of Biosystems Engineering, University of Manitoba, Winnipeg.

[20] Tofanica, B.M., Cappelletto, E., Gavrilescu, D. and Mueller, K. (2011) Properties of Rapeseed (Brassica napus) Stalks Fibers. Journal of Natural Fibers, 8, 241-262. https://doi.org/10.1080/15440478.2011.626189

[21] Kiaei, M., Mahdavi, S., Kialashaki, A., Nemati, M., Samariha, A. and Saghafi, A. (2014) Chemical Composition and Morphological Properties of Canola Plant and Its Potential Application in Pulp and Paper Industry. Cellulose Chemistry and Technology, 48, 105-110.

[22] Kozasowski, R.M., Mackiewicz-Talarczyk, M. and Allam, A.M. (2012) Bast Fibres: Flax. In: Kozłowski, R.M., Ed., Handbook of Natural Fibres: Types, Properties and Factors Affecting Breeding and Cultivation, Woodhead Publishing, Sawston, 56-113. https://doi.org/10.1533/9780857095503.1.56

[23] Macmillan, C.P. and Birke, H. (2016) Lignin Deposition in Cotton Cells? Where Is the Lignin? Journal of Plant Biochemistry \& Physiology, 1, 2-5. https://doi.org/10.4172/2329-9029.1000e106

[24] Alcock, M., Ahmed, S., DuCharme, S. and Ulven, C. (2018) Influence of Stem Diameter on Fiber Diameter and the Mechanical Properties of Technical Flax Fibers from Linseed Flax. Fibers, 6, 10. https://doi.org/10.3390/fib6010010

[25] Rahman, A., Kushwaha, R. and Alam, M. (2013) Effect of Fiber Diameter on Properties of Compression Molded Flax Fiber-Reinforced Biocomposites. International Journal of Composite Materials, 3, 122-129.

[26] Fangueiro, R. and Rana, S. (2018) Industrial Hemp Transformation for Composite Applications: Influence of Processing Parameters on the Fibre Properties. In: $A d$ vances in Natural Fibre Composites. Raw Materials, Processing and Analysis, Springer International Publishing, Berlin, Vol. 2, 13-25.

https://doi.org/10.1007/978-3-319-64641-1_2

[27] Beher, H.M. (2005) Effect of Mechanical and Physical Properties on Fabric Hand. Elsevier Inc., Amsterdam, 1-480. https://doi.org/10.1007/978-3-319-64641-1 2

[28] Collier, B.J. and Epps, H.H. (1999) Textile Testing and Analysis. Prentice Hall Pub- 
lishing, Englewood Cliffs, Vol. 7, 374.

[29] Yuan, Y. and Lee, T.R. (2013) Contact Angle and Wetting Properties. In: Surface Science Techniques, Springer, Berlin, Vol. 51, 3-34.

https://doi.org/10.1007/978-3-319-64641-1 2

[30] Bates, D., Mächler, M., Bolker, B.M. and Walker, S.C. (2015) Fitting Linear MixedEffects Models Using lme4. Journal of Statistical Software, 67, 1-48. https://doi.org/10.18637/jss.v067.i01

[31] Shuvo, I.I., Rahman, M., Duncan, R., Ducharme, S. and Choo-Smith, L. (2018) A New Generation of Textile Fibre from Canola Biomass and the Impact of Cultivar on Fibre Quality. The 91st Textile Institute World Conference (TIWC), Leeds, 2326 July 2018, 1-16.

[32] Canola Encyclopedia (2020) Growth Stages. https://www.canolacouncil.org/canola-encyclopedia/crop-development/growth-stag es

[33] Müssig, J., Fischer, H., Graupner, N. and Drieling, A. (2010) Testing Methods for Measuring Physical and Mechanical Fibre Properties (Plant and Animal Fibres). In: Müssig, J., Ed., Industrial Applications of Natural Fibres. Structure, Properties and Technical Applications, John Wiley and Sons, Hoboken, 267-309. https://doi.org/10.1002/9780470660324.ch13

[34] Nayak, R.K., Padhye, R. and Fergusson, S. (2012) Identification of Natural Textile Fibres. In: Handbook of Natural Fibres, Elsevier Ltd., Amsterdam, 314-344. https://doi.org/10.1533/9780857095503.1.314

[35] Wiegerink, J.G. (1940) The Moisture Relations of Textile Fibres at Elevated Temperatures. Textile Research Journal, 10, 357-371. https://doi.org/10.1177/004051754001000901

[36] Li, S., Huang, J., Chen, Z., Chen, G. and Lai, Y. (2017) A Review on Special Wettability Textiles: Theoretical Models, Fabrication Technologies and Multifunctional Applications. Journal of Materials Chemistry. A, Materials for Energy and Sustainability, 5, 31-55. https://doi.org/10.1039/C6TA07984A

[37] Cristaldi, G., Latteri, A., Recca, G. and Cicala, G. (2010) Woven Fabric Engineering. InTechOpen, London, 317-342.

[38] All of Textiles (2021) Jute Fibre. http://alloftextiles.com/aot jute1.aspx

[39] Kaswell, E.R. (1963) Wellington Sears Handbook of Industrial Textiles. Massachusetts Institute of Technology (MIT) and Wellington Sears Company, Cambridge.

[40] Schellbach, S., Monteiro, S. and Drelich, J. (2015) A Novel Method for Contact Angle Measurements on Natural Fibers. Materials Letters, 164, 599-604. https://doi.org/10.1016/j.matlet.2015.11.039

[41] Textile Study Center (2021) Tensile Testing Terms and Tensile Testing Terms Definitions.

https://textilestudycenter.com/tensile-testing-terms-and-tensile-testing-terms-defin itions

[42] Das, A. (2013) Testing and Statistical Quality Control in Textile Manufacturing. In: Process Control in Textile Manufacturing, Woodhead Publishing, Sawston, 41-78.

[43] Petroudy, S.R. (2017) Physical and Mechanical Properties of Natural Fibers. In: Fan, M. and Fu, F., Eds., Advanced High Strength Natural Fibre Composites in Construction, Woodhead Publishing, Sawston, 59-83.

https://doi.org/10.1016/B978-0-08-100411-1.00003-0

[44] Eltahan, E. (2018) Structural Parameters Affecting Tear Strength of the Fabrics Tents. 
Alexandria Engineering Journal, 57, 97-105. https://doi.org/10.1016/j.aej.2016.12.005

[45] Keyavlon Impex (2020) Polyester High Tenacity Yarn. 2020. http://www.kayavlon.com/phtyarn.htm

[46] Tyagi, G.K. (2010) Yarn Structure and Properties from Different Spinning Techniques. In: Lawrence, C.A., Ed., Advances in Yarn Spinning Technology, Woodhead Publishing, Sawston, 119-154. https://doi.org/10.1533/9780857090218.1.119

[47] Neagu, R.C., Gamstedt, E.K. and Berthold, F. (2006) Stiffness Contribution of Various Wood Fibers to Composite Materials. Journal of Composite Materials, 40, 663 699. https://doi.org/10.1177/0021998305055276

[48] Prasad, B.M. and Sain, M.M. (2003) Mechanical Properties of Thermally Treated Hemp Fibers in Inert Atmosphere for Potential Composite Reinforcement. Materials Research Innovations, 7, 231-238. https://doi.org/10.1007/s10019-003-0258-y

[49] Shahzad, A. (2013) A Study in Physical and Mechanical Properties of Hemp Fibres. Advances in Materials Science and Engineering, 2013, Article ID: 325085. https://doi.org/10.1155/2013/325085

[50] Property Information (2020) Young's Modulus and Specific Stiffness. http://www-materials.eng.cam.ac.uk/mpsite/properties/non-IE/stiffness.html

[51] Omnexus (2020) Stiffness. https://omnexus.specialchem.com/polymer-properties/properties/stiffness

[52] Ryu, S.-R. and Lee, D.-J. (2001) Effects of Fiber Aspect Ratio, Fiber Content, and Bonding Agent on Tensile and Tear Properties of Short-Fiber Reinforced Rubber. Journal of Mechanical Science and Technology, 15, 35-43. https://doi.org/10.1007/BF03184796

[53] Tissera, N., Wijesena, R., Jayawickramage, R., De Silva, K.M. and Amaratunge, G. (2015) Hydrophobic Cotton Textile Surfaces Using an Amphiphilic Graphene Oxide (GO) Coating. Applied Surface Science, 324, 455-463. https://doi.org/10.1016/j.apsusc.2014.10.148

[54] Charlet, K., Baley, C., Morvan, C., Jernot, J.P., Gomina, M. and Bréard, J. (2007) Characteristics of Hermès Flax Fibres as a Function of Their Location in the Stem and Properties of the Derived Unidirectional Composites. Composites. Part A, Applied Science and Manufacturing, 38, 1912-1921. https://doi.org/10.1016/j.compositesa.2007.03.006

[55] Bourmaud, A., Gibaud, M., Lefeuvre, A., Morvan, C. and Baley, C. (2016) Influence of Stem Morphology and Fibres Stiffness on the Loading Stability of Flax. In: RILEM Bookseries, Kluwer Academic Publishers, Dordrecht, Vol. 12, 49-59. https://doi.org/10.1007/978-94-017-7515-1_4

[56] Charlet, K., Jernot, J.P., Gomina, M., Bréard, J., Morvan, C. and Baley, C. (2009) Influence of an Agatha Flax Fibre Location in a Stem on Its Mechanical, Chemical and Morphological Properties. Composites Science and Technology, 69, 1399-1403. https://doi.org/10.1016/j.compscitech.2008.09.002

[57] Morton, W. and Hearle, J. (2008) Physical Properties of Textile Fibres. 4th Edition, Woodhead Publishing, Cambridge, 163-167. https://doi.org/10.1533/9781845694425.163

[58] Moudood, A., Hall, W., Öchsner, A., Li, H., Rahman, A. and Francucci, G. (2019) Effect of Moisture in Flax Fibres on the Quality of Their Composites. Journal of Natural Fibers, 16, 209-224. https://doi.org/10.1080/15440478.2017.1414651

[59] ASTM D5229 (2004) Standard Test Method for Moisture Absorption Properties and 
Equilibrium Conditioning of Polymer Matrix Composite Material. ASTM International, West Conshohocken.

http://file.yizimg.com/175706/2014021816594640.pdf 